\title{
Research on Countermeasures of Mental Health Education Based on Personality Deviation of Secondary Vocational Students
}

\author{
Zirui Zhang, Liqin $\mathrm{Yu}^{*}$ \\ School of Education and Psychological Science, Jinan University, Jinan, China \\ *Corresponding author. Email: 17854177357@163.com
}

\begin{abstract}
Personality deviation is a bad state of personality development, manifested as developmental psychological problems, adaptive psychological problems, personality disorders psychological problems. Secondary vocational students are susceptible to personality deviation because of their education types and the particularity of their physical and mental development stage. Based on the theory of junior high school students' personality structure proposed by Yang lizhu et al., this paper puts forward corresponding measures of mental health education for the five dimensions of extroversion, intelligence characteristics, earnest self-control, emotional stability and prosociality, so as to achieve the goal of cultivating sound personality and professional ethics of secondary vocational students.

At the 2018 National Education Conference, General Secretary Xi Jinping made it clear that Enhance Morality and Foster Talents should be run through the field of vocational education, and should be integrated into ideological and moral education, cultural knowledge education, and social practice education. However, under the complicated background of social temptations and fierce professional competition, secondary vocational students in the transition period of physical and mental development will inevitably have a variety of psychological confusion and problems in the process of learning life from the general education to vocational education, Leading to psychological imbalances and personality deviations. At present, most of the research is devoted to proposing educational countermeasures on how to develop healthy personality of secondary vocational students, and there are few studies on mental health countermeasures on how to break the psychological imbalance and make up for the lack of specific personality dimensions of secondary vocational students.
\end{abstract}

Keywords: Secondary vocational students, personality bias, countermeasures of mental health education

\section{INTRODUCTION}

Personality is the sum of unique and relatively stable psychological characteristics formed by the constraints of the acquired social life environment on the basis of biological inheritance [1]. The personality characteristics of adolescents show complexity and differences in various specific cultural situations [2]. Mental health refers to that all aspects of psychology and the whole process of activities are in a normal or good state, including emotional health, behavior coordination, interpersonal relationship adaptation, sound will and moderate response, etc. Personality is closely related to mental health. According to Maslow's Theory of Self-actualization, the need for self-actualization is the highest level of need, based on various physiological and psychological needs. When the physical needs are met, the psychological needs will dominate and wait for satisfaction, and the stride toward the highest level of self-actualization needs, which are the internal driving force for the formation and development of personality [3]. Therefore, a healthy psychology is the primary prerequisite for the formation and development of a healthy personality. Meanwhile, the shaping of a healthy personality is conducive to the improvement of psychological quality and the balanced development of individual body and mind.

As a group of teenagers with an age span of 15 to 18 years old, secondary vocational students are in the period of the most drastic psychological changes, which have both the common psychological characteristics of teenagers and the unique particularity [4]. Influenced by factors such as school atmosphere, family background and social environment, secondary vocational students, as a special group, face more complex and diverse psychological problems. Practical problems, such as frustrated study and poor interpersonal relationship, tend to lead to psychological contradictions and conflicts among secondary vocational students, and then lead to personality deviation problems such as negative emotions and inferiority complex [5]. Low self-esteem and high negative emotions will increase the incidence of risky behaviors [6]. In order to reduce the occurrence level of accidents and 
accidental injuries, we should pay more attention to the mental health problems of secondary vocational students and help them master effective self-regulation methods. From the perspective of psychology, secondary vocational students are in the critical stage of personality development -- the "second crisis period". It is of great significance to explore the possible or existing psychological crisis and problems of students, and to put forward targeted countermeasures for mental health education for secondary vocational students to develop sound personality and professional ethics.

\section{PERSONALITY DEVIATION OF SECONDARY VOCATIONAL STUDENTS}

\subsection{Definition of Personality Deviation}

The uniqueness of the individual and the interaction with the acquired environment determine the characteristics of complexity, difference and development of personality. . This makes the personality in a rheological state, constantly changing under the combined efforts of many parties. Healthy personality is a comprehensive, harmonious and healthy development of good personality status, which can fully reflect the individual personality characteristics while adapting to the social environment. When the internal indicators of healthy personality are out of balance, a bad state of personality development will be generated, that is, personality deviation. The personality development deviation is located in the middle of the path from healthy personality to personality disorder, which is manifested in disordered values, weak self-consciousness, weakened self-control, lack of moral quality, and the breeding of unhealthy psychological state. The common bad psychological states include inferiority, negativity, excessive pessimism, loneliness, paranoia, vanity, egocentricity, procrastination, shyness, cowardice, bigotry, hostility, indifference, numbness, impulsiveness and destruction, etc. Personality deviation is not achieved overnight, it is due to the bad psychological state cannot be eliminated and excluded, long-term depression in the individual and slowly generated. Personality deviation is usually externalized into three manifestations: one is developmental psychological problems, such as lack of self-confidence or arrogance, too high or low ambition goals, lack of responsibility; the second is adaptive psychological problems, mainly refers to normal people have difficulties in adapting The third is individual psychological problems such as anxiety, depression, obsessive-compulsive disorder, and suspected illness.

\subsection{Reasons for Personality Deviation of Secondary Vocational Students}

Secondary vocational school students are susceptible to personality deviation. By horizontal comparing the secondary vocational school students with the general high school students in the same period, it is found that due to incomplete current vocational education development planning, the development of mental health education in vocational schools lags behind, the academic achievements of vocational students are generally low, and the parents 'socioeconomic status and the overall level of education is behind and other factors. The growth and learning environment of secondary vocational students is relatively poor, and the pressure from peers is stronger, which is more likely to cause psychological imbalances and personality deviations. The longitudinal comparison between secondary vocational students and the same type of vocational students shows that secondary vocational students are in the early stage of immature thinking, and their body and mind are still in a state of development. At the same time, due to the rapid conversion of education types, student roles, and interpersonal relationships, secondary vocational students with weak cognitive ability and autonomous learning ability are easily defeated by small difficulties and small setbacks in learning and activities. When a variety of psychological problems or personality deviations occur, it will undoubtedly give secondary vocational students growth and life covered with a dark veil, hindering the normal learning, interpersonal communication and healthy development of students, and may even evolve into a personality disorder, we must pay great attention to.

\subsection{The Personality Deviation of Secondary Vocational Students in Each Dimension}

Taking into account the fact that secondary vocational students are students who enter secondary vocational schools to study after graduating from junior high school, this paper proposes that the mental health education strategy for secondary vocational school students based on personality deviation is based on the personality structure of junior high school students proposed by Yang Lizhu and other scholars in China. The theory combines the current situation of education and the characteristics of students in China, and is put forward through exploratory and confirmatory factor analysis. The personality structure is composed of five dimensions: extroversion, intelligent characteristics, serious self-control, emotional stability, and prosociality [1]. Secondary vocational students with a lack of extroverted dimension are characterized by strong and tired, negative and pessimistic, not very talkative and uncommunicative. Such students are cold and withdrawn, and often have poor relationships with classmates, teachers and parents. Secondary vocational students with missing intellectual characteristics will exhibit backward academic performance, poor learning autonomy, rigid thinking, and lack of exploration and innovation. Secondary vocational students with unbalanced emotional stability usually show traits such as sensitive anxiety, irritability, irritability, melancholy, mood swings, etc. In severe cases, anxiety, depression, emotional regulation disorders, psychological 
distortion and other problems will occur. It has an unimaginable and bad influence on the normal life of secondary vocational students, and even affects the safety of themselves and others. The lack of pro-social dimension of secondary vocational students will bring about the problems of distinguishing right from wrong, weak moral and legal awareness, and indifference towards life [7], which is not conducive to personal qualities such as cooperation, care, and sharing and the development of professional ethics.

\section{COUNTERMEASURES FOR MENTAL HEALTH EDUCATION OF SECONDARY VOCATIONAL STUDENTS WITH PERSONALITY DEVIATION}

\subsection{Mental Health Education Countermeasures for the Lack of Extroversion Dimension}

Extroversion refers to the degree of individual attention to the outside world and the energy devoted to the outside world. Therefore, arranging moderate sports and regularly holding collective activities is the first choice to make up for the lack of this dimension. Moderate physical exercise can improve students' physical fitness and immunity, and have a positive impact on many aspects of mental health development such as regulating emotions, cultivating willpower, promoting cognitive development, and strengthening the adaptability of the social environment. Secondly, in order to alleviate and eliminate the communication barriers of secondary vocational school students, and guide the secondary vocational school students with personality deviation to return to the right track, on the one hand, the school should strengthen the development of physical education curriculum, on the other hand, through the organization of diverse collective activities and social practice, enrich the students' after-school life, meet the students' spiritual needs, and achieve the purpose of cultivating a sound personality. Studies have shown that collective activities, especially collective sports, have a significant effect on the improvement of students' cooperation and interpersonal skills.

\subsection{Mental Health Education Countermeasures for the Lack of Intellectual Characteristic Dimension}

Intellectual characteristics are personality characteristics and behaviors with good adaptability related to intelligence. Vocational education, as an important stage of technical personnel training, should shoulder the responsibility of training students with innovative thinking and innovation ability, and "pull a handle" to students with poor performance, and help to students with poor ability, so as to make up for the lack of secondary vocational students' intellectual characteristics. Schools should actively promote the secondary vocational curriculum reform, focus on creating school-based courses of mental health that can reflect the professional characteristics of vocational schools, fully mobilize students' learning autonomy, and improve the professional knowledge and skills of secondary vocational students through a variety of development approaches. The construction of school-based curriculum needs to pay attention to three aspects: one is based on the "people-oriented" scientific development concept, and truly implement the educational concept of "promoting the physical and mental health of every vocational student"; The second is to create a diversified mental health school-based curriculum format that is practical and integrates the tripartite needs of students, teachers and schools while fully considering the local characteristics and educational resources of vocational schools; The third is to emphasize innovation. School-based curriculum is based on advanced technology and solid theory and embodies the spirit of innovation and development, so as to ensure that the school-based curriculum of mental health has pertinence, professionalism, practicality and development, and finally achieve the purpose of cultivating the innovative thinking and innovation ability of secondary vocational school students.

\subsection{Mental Health Education Countermeasures for the Lack of Serious Self-Control Dimension}

Serious self-control refers to the rigorous attitude in daily life and the planned ability to control their own behavior. Aiming at the vocational students who lack the serious self-control dimension, the countermeasures of mental health education focusing on developing hidden courses are proposed. Through the advantages of contextuality and persistence of hidden courses, students are allowed to internalize the Words and manners, emotional attitudes and moral behaviors of excellent educators into their own qualities, and cultivate excellent middle school students who are strict in discipline and firm in belief. vocational schools need to design the campus environment scientifically and reasonably. The construction of hidden curriculum is divided into three parts: one is the material aspect, vocational schools need to design the campus environment scientifically and reasonably. Combining the professional characteristics of the colleges and particularly highlighting the school's policy and educational philosophy, we know that a pleasing campus environment has a subtle and powerful educational effect. The second aspect is the form of communication, all teachers and administrators of vocational schools should lead by example, cultivate their own healthy personality and positive psychological quality, become an example that students can learn and follow, strengthen sincere 
communication and exchange with students, and guide teachers and students Form an equal and harmonious interpersonal relationship, and enhance the trust and friendship between teachers and students. The third is the spiritual aspect: focus on building a democratic and equal organizational system relationship, highlight the positive campus cultural atmosphere, and use the "sunshine campus" as the basis to deliver healthy and positive energy to vocational students.

\subsection{Mental Health Education Countermeasures for the Lack of Emotional Stability Dimension}

Through the comprehensive application of various evaluation methods such as questionnaire, natural observation, structural or semi-structural interview and so on, we can judge the specific psychological problems of the secondary vocational school students with personality deviation, and then form the corresponding mental health education countermeasures with different stages and specialties.

For example, for the secondary vocational school students with anxiety or depression, the combination of physical exercise and psychological counseling should be selected. Different intensity and rhythm of sports activities can have a certain intervention effect on the participants, and consume the negative energy that students with personality deviation have been depressed for a long time. Specifically, when the treatment of anxiety, the choice of sports can be swimming, mountain climbing and other more interesting activities. Psychological counseling is mainly conducted by professional mental health teachers, such as Morita therapy, relaxation therapy or biotechnology feedback. When the treatment of depression, The treatment method is to choose the collective sports with more skills, such as football, basketball and other long-lasting ball games, which will help to improve the excitement of students and the frequency of communication with others in the process of playing. Psychological counseling is a combination of peer counseling and teacher counseling. The advantage of peer counseling is that the counselor is also a student, which is easy to resonate with and gain trust with the client, so that the client can lay down his guard, open his heart and increase the probability of success of psychological counseling. Secondary vocational students with sensitive and fragile personality are prone to appear anxiety, depression, high aggression and other externalized personality deviations, so accurate warning and timely intervention in the development of psychological crisis. In the design and implementation of the intervention measures, it is necessary to be specific and in-depth, take the class as the unit, carry out "psychological dynamic analysis and evaluation" for secondary vocational school students, record the psychological state of students in different stages. so as to provide clues for psychological guidance and improve the initiative and accuracy of psychological education. In the assessment process, the secondary vocational school students with psychological problems and personality deviation are screened through psychological test, interview and self-report. The psychological files of students are established and the confidentiality work is done well, so as to help the students get through the psychological crisis smoothly and correct the status of personality deviation.

\subsection{Mental Health Education Countermeasures for the Lack of Pro-Social Dimension}

The study and application of positive psychology should be vigorously promoted in vocational schools to promote students' experience of positive emotions, cultivate students' positive personality, and help them integrate into social life. On the one hand, combined with the development characteristics and personality differences of secondary vocational students, the theoretical knowledge of positive psychology is selectively integrated into the classroom of vocational schools. On the other hand, the curriculum of positive mental health education is specially set up to guide students to feel and experience happiness, and to teach students simple methods of self-troubleshooting and Self-relief, so that students can recognize the shortcomings in their own personality development, accept the defects and actively correct them, so that students can purify themselves in the learning process. In addition, the school should regularly hold a wide range of psychological lectures, including: social hot topics or phenomena, socialist core values, excellent traditional culture of the Chinese nation, introduction of moral model and professional model, employment situation analysis or employment guidance, mental health education seminar, etc.At present, many vocational schools in China are in the process of positive psychology practice exploration, and it is expected that there will be a successful application program of positive psychology for reference in the near future.

\section{SUMMARY}

Secondary vocational students are prone to personality deviation due to its particularity, that is, the absence of personality between the various dimensions, resulting in psychological state imbalance. This imbalance can be broken through the joint efforts of secondary vocational students themselves, schools and society. It is the responsibility of educational and teaching researchers and front-line educators to actively guide students to understand their own personality deficiencies, patiently analyze the possible problems in all dimensions of personality, and make detailed, diversified and scientific countermeasures for mental health education. The development in the new era urgently requires high-level vocational and technical personnel with excellent skills 
and high qualities, and this requires the use of sound personality and healthy psychology as a solid foundation.

\section{REFERENCES}

[1] Yang Lizhu.Thirty Years of Research on the Development and Cultivation of Personality of Chinese Children and Adolescents [J]. Psychological Science, 2015, (31):9-14.

[2] De Young,C.G.Personality neuroscience and the biology of traits[J].Social and Personality Psychology Compass,2010,4 ( 12 ):1165- 1180.

[3] Chen Li. The application of Maslow's self realization theory in the cultivation of College Students' sound personality [J]. Heilongjiang Higher Education Research, 2008, 168(4),132-134.

[4] He Zhichang.Mental health status of middle vocational students and exploration of educational countermeasures $[\mathrm{J}]$. Education Research and Experiment, 2017, (5), 91-94.

[5] Wang Yao.Exploration of the Mental Health Education Model of Secondary Vocational School Students in the New Period [J] Academic Forum, 2013, (2),211-214.

[6] Tang Qingrong. Correlation analysis of health literacy and health risk behaviors among students in private higher vocational colleges in Shanghai [J]. Chinese School Health, 2014, 35( 4):514-516.

[7] Liu Songhan, Yang Lizhu. On the Strategies of Sound Personality Training for Secondary Vocational Students [J]. Moral Education Research, 2015, (04), 90-95. 